\title{
"HEALTHIER” AND "LESS HEALTHY” CLASSIFICATIONS ACCORDING TO THREE NUTRIENT PROFILING SYSTEMS RELATIVE TO NUTRITION AND HEALTH CLAIMS ON FOOD LABELS
}

\author{
K. DebeljaK ${ }^{\mathrm{a}}$, I. Pravst ${ }^{\mathrm{b} *}, \mathrm{~K} . \mathrm{KoŠMelj}^{\mathrm{c}}$ and M. KaČ ${ }^{\mathrm{a}}$ \\ ${ }^{a}$ Department of Food Science and Technology, Biotechnical Faculty, University of Ljubljana, Jamnikarjeva 101, \\ 1000 Ljubljana. Slovenia \\ ${ }^{b}$ Nutrition Institute, Tržaška cesta 40, 1000 Ljubljana. Slovenia \\ ${ }^{c}$ Department of Agronomy, Biotechnical Faculty, University of Ljubljana, Jamnikarjeva 101, 1000 Ljubljana. \\ Slovenia \\ †This paper is dedicated to the memory of Professor Milica Kač (1953-2014)
}

(Received: 9 May 2014; accepted: 13 July 2014)

\begin{abstract}
A comprehensive sample of breakfast cereals (a total of 221 breakfast cereals available in the market) were compared according to their nutritional composition, being analysed using three nutrient profiling systems to categorise foods as "healthier" or "less healthy". Differences were further on investigated focusing on the use of nutrition and health claims on the labelling. The aim was to determine how much the use of such a claim corresponds to the categorisation into "healthier" or "less healthy" group.

The sample contained $161(72.9 \%)$ items with claims and $60(27.1 \%)$ items, without claims. The nutrient profiles of the foods were determined by the UK Ofcom model, the FSANZ model and the modified Traffic Light model. All the models use similar but nevertheless different ways of determining the final score of "healthier" or "less healthy". The percentage of foods classified as "healthier" was well below $72.9 \%$ (from $24.8 \%$ to $52.2 \%$ ), indicating that profiling with each model involves stricter criteria for the classifying of foods compared to the permission to carry a nutrition and/or health claim. The difference is the most pronounced for the modified Traffic Light system, while the UK Ofcom and FSANZ systems give results closer to the use of claims.
\end{abstract}

Keywords: nutrient profiling, UK Ofcom model, FSANZ model, Traffic Light model, breakfast cereals, nutrition claims, health claims

It is well recognised that diet can contribute to long-term health and well-being beyond simply providing basic nutrition. However, in the developed world a significant part of the population nowadays has a wide access to a variety of foods and their daily routine requires low physical activity. Due to these changes, balancing one's energy intake and expenditure has become difficult, resulting in increased prevalence of chronic, non-communicable diseases. It is clear that diet, physical inactivity, and lifestyle all play a role in the growing incidence of these diseases, and the efficiency of our efforts to reduce them will depend on striking a balance between these three factors. To help consumers make healthy dietary choices, various nutrient profile models were developed that classify foods into "healthier" and "less healthy" (Tetens et al., 2007; EUfiC, 2008; Verhagen \& Van Den Berg, 2008). Nutrient profiling is defined as the "science of classifying or ranking foods according to their nutritional composition for reasons related to preventing of disease and promoting health"

\footnotetext{
* To whom correspondence should be addressed.

Phone: +386-590-68871; fax: +386-130-07981; e-mail: igor.pravst@nutris.org
} 
(WHO, 2011). Although nutrient profile models cannot cover all aspects of nutrition and health, they can also be useful for educating consumers, improving knowledge about nutrition, and suitable for regulating the labelling of pre-packed foods. By considering a suitable nutrient profiling system, consumers can make a better distinction between "healthier" and "less healthy" food (AZAïs-BRAESCO et al., 2006).

A nutrient profiling system can be used for various purposes: regulating food labelling, product labelling with symbols, identifying food products eligible to carry nutrition or health claims, informing and educating consumers, helping consumers in their healthy food choices, and regulating the advertising of foods for children (Tetens et al., 2007; SCARBorough et al., 2007a,b; Verhagen \& Van Den Berg, 2008). The introduction of nutrient profiles was also provided in the European regulation on nutrition and health claims made on foods, although this part of the legislation has yet to be implemented (CAPPUCCIO \& Pravst, 2011).

Numerous nutrient profiling models have been developed, all enabling the classification of foods according to their nutritional composition (GARSETTI et al., 2007; VerHAGEN \& VAN Den Berg, 2008). The nutrient profiling systems vary with regard to their: (1) categorisation of foods; (2) reference values; (3) use of thresholds and/or scoring; and (4) selection of nutrients and other food constituents that are considered in the evaluation of the balance between "positive" and "negative" nutrients (GARSETTI et al., 2007; Trichterborn \& Harzer, 2007). While energy density and the content of fat, saturated fatty acids, sugars, and sodium/ salt are usually seen as negative factors, several models also consider positive components, such as the content of protein, fibre, fruit, vegetables, and nuts (RAYNER et al., 2009; FSANZ, 2011). Several of such nutrient profile models are currently used in practice, for example: in the United Kingdom, the UK Ofcom (Office of Communications) nutrient profile model is used to regulate the advertising of food to children (RAYNER et al., 2009). The model was developed by the Food Standards Agency (FSA) following calls by consumer and public health organisations to ban advertising of "unhealthy" food to children. The FSA has also developed the Traffic Light model for evaluating the nutritional value of pre-prepared foods and to help consumers make healthier food choices as well as to reduce their daily intake of fat, saturated fatty acids, sugars, and salt (FSA, 2007). In Australia and New Zealand, the FSANZ (Food Standards Australia New Zealand) nutrient profile model has been developed as a tool to regulate the use of health claims on foods (FSANZ, 2011).

Labels on pre-packed food should provide consumers with all information about the product needed to allow an informed choice. The labelling of pre-packaged food is defined by law (EC, 2011) and divided into statutory and voluntary labelling. Up until the end 2016, the labelling of a nutrition declaration for pre-packed foods will not be statutory in the EU, except when nutrition or health claims are used.

Breakfast cereals are generally considered a healthy dietary choice. However, high energy density and especially high sugar content can be questionable in many products on the market. The aim of the study is twofold: a) to gain an insight into the composition of breakfast cereals generally sold in the market; and b) to correlate the results of nutrient profiling of these products according to three commonly used nutrient profiling systems (UK Ofcom model, FSANZ model and Traffic Light model). In addition, the results were compared with the classification specified for nutrition or health claims on food labels (EC, 2006; PrAVST, 2012). 


\section{Materials and methods}

\subsection{Collecting the samples and data included in the study}

The sample included 221 breakfast cereals that were available in selected grocery stores at the time of sampling during summer 2013. Sampling was carried out in grocery stores of the three most important retailers with a share of sales exceeding $60 \%$ of the market in Slovenia (mega-market, supermarket, and a discounter). The packaging of all available breakfast cereals was photographed; data extracted from the photographs were used to compose a database containing the product composition and other labelling information (i.e. use of claims), enabling the nutrient profile models to be employed.

The 221 specimens (Group A (all)) were divided into two groups: the first group (Group B (claims)) included products labelled with nutrition and/or health claims, while the second one (Group C (no claims)) included products with no such claims. Three different nutrient profiling systems (UK Ofcom, FSANZ and Traffic Light) were applied to the full sample of foods. Finally, the results of the nutrient profiling models were correlated with the presence or absence of nutrition and/or health claims.

\subsection{Details of the models used}

1.2.1. The UK Ofcom nutrient profile model. The UK Ofcom nutrient profile model is a points-based model. Points for nutrients are allocated on the basis of the nutritional content in $100 \mathrm{~g}$ of a food or drink. Final points are based on summarising the number of points for "negative" (energy, saturated fatty acids, sugars, and sodium) and "positive" components (protein, fibre and fruit, vegetables, and nuts). Positive values are allocated to "negative" components, while negative values are allocated to "positive" components. If a food scores 4 points or more, it is classified as "less healthy", while for drinks such a threshold is at 1 point (RAYNer et al., 2009).

1.2.2. The FSANZ nutrient profile model. The FSANZ nutrient profile model is another points-based model (FSANZ, 2011), which is a modified version of the UK Ofcom model and is used in Australia and New Zealand to regulate the use of health claims on foods. Similarly, points are allocated based on the nutritional composition per $100 \mathrm{~g}$ of food product. The final assessment is obtained by summarising the "negative" points (points for energy, saturated fatty acids, total sugars, and sodium) from which the positive points for protein, fibre, and points for fruit, vegetables, and nuts are subtracted. Foods are classified into three categories: (1) beverages; (2) all other foods; and (3) oils, oil spreads, and cheese high in calcium. Each category has different cut-off points for determining whether a food is eligible to carry a health claim. The use of health claims is allowed on foods that are given less than 1 point for category 1 , less than 4 points for category 2 , and less than 28 points for category 3. Consequently, also in this study, those were considered as "healthier" (FSANZ, 2011).

1.2.3. The modified Traffic Light model. The modified Traffic Light model only includes "negative" nutrients. The evaluation is presented in colour, which indicates the level of fat, saturated fatty acids, sugars, and salt per $100 \mathrm{~g}$ of food product (FSA, 2007). A red colour indicates a "high" level of each nutrient; an amber colour indicates a "medium" level and a green colour indicates a "low" level of the nutrient in question. Although in practice this 
model was not developed as a scoring system, it has been used as such. The modified Traffic Light model assigns points for every colour: 1 point for every green colour, 2 points for every amber colour, and 3 points for every red colour, giving a total possible of 12 points. Products scoring less than 7 points are considered "healthier" and products scoring 7 points or more are considered "less healthy" (SACKS et al., 2009; 2011).

\subsection{Statistical analysis}

Statistical analyses were conducted using statistical programming language $\mathrm{R}$, which is a free software environment for statistical computing and graphics (R CORE TEAM, 2013). The data on nutrient composition are presented as mean \pm standard deviation, as well as by the minimum and maximum. A comparison of the mean values between Group B (claims) and Group C (no claims) was evaluated with a $t$-test, and different variances were taken into account if necessary (Welch $t$-test). Distributions of the Ofcom points and FSANZ points were obtained using a standard smoothing technique for density estimation, while for the modified Traffic Light model, the distributions are presented as histograms. Smoothing technique would not be relevant in this case, because there are only 8 values in the range from 4 to 11, while the ranges are much larger for Ofcom and FSANZ models. For each model, the density for Group B (claims) and Group C (no claims) was compared graphically. The outcomes of the "healthier" and "less healthy" classifications obtained by the three models were compared with the outcome of the nutrient/health classification on food labels. For each classification, a $2 \times 2$ contingency table was obtained. To compare two classifications, McNemar's test of symmetry was used. Under the null hypothesis, two classifications are identical and the $2 \times 2$ matrix is diagonal; McNemar's chi-square statistics tests the symmetry of this matrix (AGRESTI, 1990).

\section{Results and discussion}

Table 1 gives values for nine nutritional components relevant to the allocation of points when profiling food. As expected, the mean values for all negative nutritional components (1 to 6) are lower in Group B (claims) than in Group C (no claims), and they are higher for all positive ingredients (7 to 9). However, large standard deviations were observed in all three groups, reflecting large variability in each of the three groups due to the significant differences between the foods described as breakfast cereals. The P-values obtained by comparing the means for Group B (claims) and Group C (no claims) reveal statistically notable differences in the means for energy value $(\mathrm{P}=0.0000)$, fat content $(\mathrm{P}=0.0439)$, content of sugars $(\mathrm{P}=0.0000)$, proteins $(\mathrm{P}=0.0002)$, and fibre $(\mathrm{P}=0.0000)$; a marginally significant difference was obtained for the contents of saturated fatty acids $(\mathrm{P}=0.0783)$, while no statistically significant differences were found for contents of sodium, salt, and in the percentage of fruit, vegetables, and nuts. Groups with P-value lower than 0.05 were considered statistically significantly different.

In Table $1 \mathrm{~min}$ and max values for each variable are presented (as given on the label of the cereal). (The corresponding mean and SD are presented with one additional digit.)

Table 1 compares group $\mathrm{B}$ and group $\mathrm{C}$ for each variable separately. This is not a multiple comparison. Comparing nine nutritional components simultaneously requires multicomparison correction; corrected significance level according to Bonferroni is $0.05 / 9=0.0056$, meaning that one gets significantly different values for energy, sugars, proteins, and fibre. 
Table 1. Means, standard deviations (SD), minimum, and maximum for each nutritional component and each group under investigation; mean comparison of Group B (claims) $(n=161)$ and Group C (no claims) $(n=60)$ for each nutritional component

\begin{tabular}{|c|c|c|c|c|}
\hline Nutritional component & $\begin{array}{c}\text { Group A (all) } \\
n=221\end{array}$ & $\begin{array}{c}\text { Group B (claims) } \\
n=161\end{array}$ & $\begin{array}{c}\text { Group C } \\
\text { (no claims) } \\
n=60\end{array}$ & $\begin{array}{l}\text { Mean comparison } \\
\text { between B } \\
\text { (claims) and C } \\
\text { (no claims) } \\
\text { P-value for } t \text {-test }\end{array}$ \\
\hline \multicolumn{5}{|l|}{1 Energy $(\mathrm{kJ} / 100 \mathrm{~g})$} \\
\hline Mean \pm SD & $1631.1 \pm 172.6$ & $1601.8 \pm 170.0$ & $1709.5 \pm 155.2$ & $\mathrm{P}=0.0000 * * *$ \\
\hline Min-max & 968-2079 & 968-2009 & 1410-2079 & \\
\hline \multicolumn{5}{|l|}{2 Fat (g/100 g) } \\
\hline Mean \pm SD & $7.38 \pm 5.68$ & $6.85 \pm 5.16$ & $8.81 \pm 6.74$ & $\mathrm{P}=0.0439 *$ \\
\hline Min-max & $0.4-26.0$ & $0.7-23.96$ & $0.4-26.0$ & \\
\hline \multicolumn{5}{|c|}{3 Saturated fatty acids (g/100 g) } \\
\hline Mean \pm SD & $2.76 \pm 2.89$ & $2.55 \pm 2.82$ & $3.32 \pm 3.03$ & $\mathrm{P}=0.0783$ \\
\hline Min-max & $0.0-17.6$ & $0.0-17.6$ & $0.2-11.0$ & \\
\hline \multicolumn{5}{|l|}{4 Sugars (g/100 g) } \\
\hline Mean \pm SD & $18.75 \pm 11.6$ & $16.88 \pm 11.16$ & $23.78 \pm 11.39$ & $\mathrm{P}=0.0000 * * *$ \\
\hline Min-max & $0.0-45.0$ & $0.0-45.0$ & $0.7-45.0$ & \\
\hline \multicolumn{5}{|l|}{5 Sodium $(\mathrm{mg} / 100 \mathrm{mg})$} \\
\hline Mean \pm SD & $227.32 \pm 302.67$ & $208.85 \pm 232.47$ & $276.89 \pm 437.74$ & $\mathrm{P}=0.2559$ \\
\hline Min-max & $0.4-3100.0$ & $0.4-1500.0$ & $4.0-3100.0$ & \\
\hline \multicolumn{5}{|l|}{6 Salt (g/100 g) } \\
\hline Mean \pm SD & $0.58 \pm 0.76$ & $0.53 \pm 0.58$ & $0.69 \pm 1.09$ & $\mathrm{P}=0.2677$ \\
\hline Min-max & $0.0-7.8$ & $0.0-3.8$ & $0.0-7.8$ & \\
\hline \multicolumn{5}{|l|}{7 Proteins (g/100 g) } \\
\hline Mean \pm SD & $9.65 \pm 3.30$ & $10.04 \pm 3.60$ & $8.59 \pm 1.99$ & $\mathrm{P}=0.0002 * * *$ \\
\hline Min-max & $4.5-36.9$ & $5.0-36.9$ & $4.5-13.5$ & \\
\hline \multicolumn{5}{|l|}{8 Fibre (g/100 g) } \\
\hline Mean \pm SD & $7.97 \pm 6.04$ & $8.81 \pm 6.77$ & $5.7 \pm 2.27$ & $\mathrm{P}=0.0000 * * *$ \\
\hline Min-max & $0.2-45.0$ & $0.9-45.0$ & $0.2-10.8$ & \\
\hline \multicolumn{5}{|l|}{$9 \%$ fruit, vegetable, nuts } \\
\hline Mean \pm SD & $4.64 \pm 14.88$ & $4.89 \pm 14.92$ & $3.94 \pm 14.88$ & $\mathrm{P}=0.6705$ \\
\hline Min-max & $0.0-63.8$ & $0.0-63.8$ & $0.0-63.8$ & \\
\hline
\end{tabular}

*: significant at $\mathrm{P}<0.05$; ***: significant at $\mathrm{P}<0.001$

Figure 1 shows the comparison of densities for B group (claims) and C group (no claims) for the Ofcom and FSANZ profiling models. Generally, the results are similar. In both cases, the B group (claims) densities have two similarly expressed peaks, showing that approximately half of these items are in the "healthier" and half in the "less healthy" section. The C group (no claims) densities have one dominant peak in the "less healthy" section. Figure 2 presents the histograms of Traffic Light points for the B (claims) group and C (no claims) group. In this case, the shapes of the histograms are surprisingly similar.

Table 2 presents these results in a different way. The percentage of items in "healthier" and "less healthy" category for each group (A (all), B (claims), and C (no claims)) and for each profiling system is given. As expected, the group with claims (B) includes the highest fraction of "healthier" products and that with no claims $(\mathrm{C})$ the lowest. 

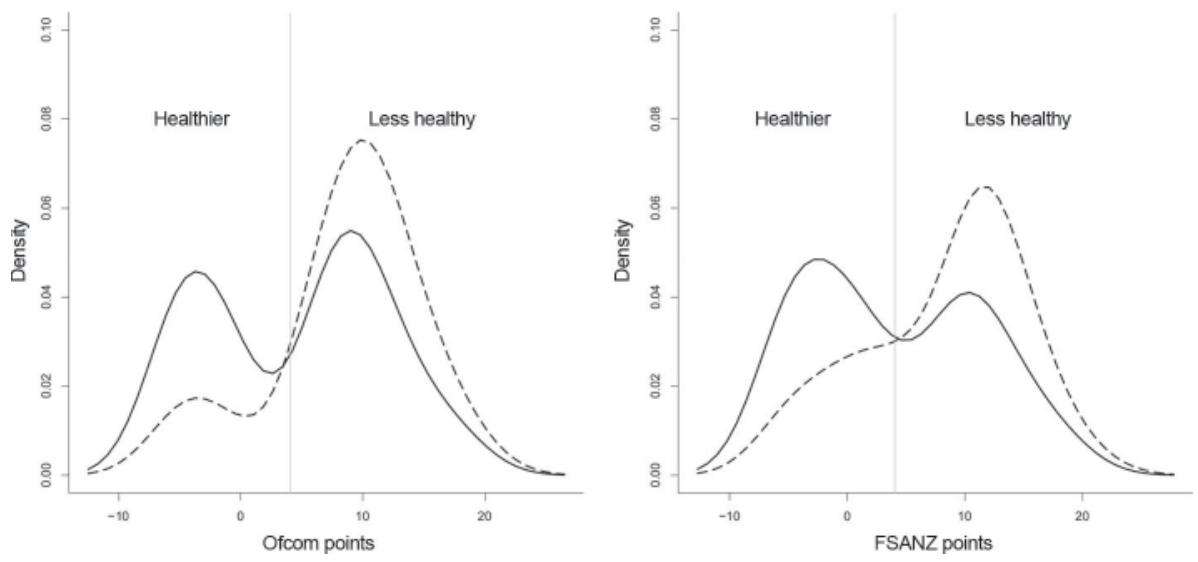

Fig. 1. Comparison of densities for points scored by the UK Ofcom model for Group B (claims) and Group C (no claims) (left) and by the FSANZ model for the same two groups (right). — : B (claims); - - - C (no claims)
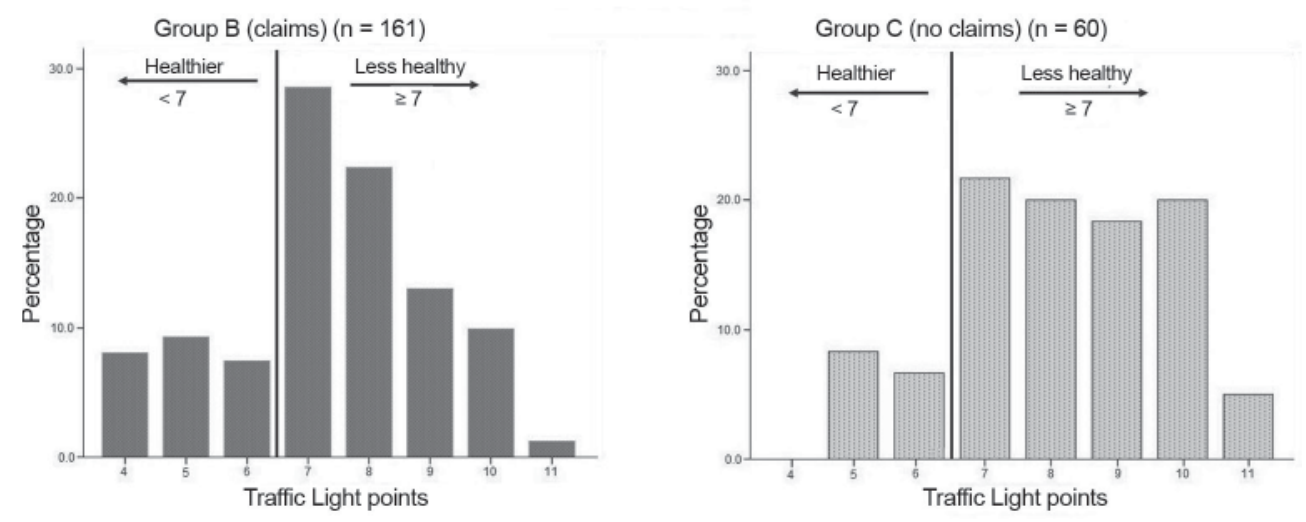

Fig. 2. Histograms showing the percentage of items vs. points scored for Group B (claims) by the modified Traffic Light model (left) and for Group C (no claims) by the same model

According to the use of nutrition and/or health claims, which were found on $72.9 \%$ of the specimens in Group A (all), we had expected the "healthier" score for far more specimens than turned out to be the case. If we compare the $72.9 \%$ of specimens in Group A (all) with the percentage that were scored "healthier" by the three models: $45.2 \%$ for the FSANZ model, $34.8 \%$ by the UK Ofcom model, and $20.8 \%$ by the modified Traffic Light model, we cannot but observe that the fact of carrying a nutrition and/or health claim corresponds very poorly to the "healthier" and "less healthy" scores given by any of the three models included in this study. Even the FSANZ model, which has been developed to function as a tool for regulating the use of health claims of foods (FSANZ, 2011), fails to match this demand. 
Table 2. Percentage of items in "healthier" and "less healthy" breakfast cereals as determined for Group A (all) $(\mathrm{n}=221)$, Group B (claims) $(\mathrm{n}=161)$ and Group C (no claims) $(\mathrm{n}=60)$ by the UK Ofcom, FSANZ and Traffic Light models

\begin{tabular}{|c|c|c|c|c|c|c|}
\hline \multirow[t]{2}{*}{ Groups } & \multicolumn{2}{|c|}{ UK Ofcom $^{\mathrm{a}}$} & \multicolumn{2}{|c|}{ FSANZ $^{\mathrm{b}}$} & \multicolumn{2}{|c|}{ Traffic Light $^{\mathrm{c}}$} \\
\hline & $\begin{array}{l}\text { HEALTHIER } \\
\text { ( }<4 \text { points })\end{array}$ & $\begin{array}{c}\text { LESS } \\
\text { HEALTHY } \\
\text { ( } \geq 4 \text { points) }\end{array}$ & $\begin{array}{l}\text { HEALTHIER } \\
\text { (<4 points) }\end{array}$ & $\begin{array}{c}\text { LESS } \\
\text { HEALTHY } \\
(\geq 4 \text { points) }\end{array}$ & $\begin{array}{l}\text { HEALTHIER } \\
<7 \text { points }\end{array}$ & $\begin{array}{c}\text { LESS } \\
\text { HEALTHY } \\
\geq 7 \text { points }\end{array}$ \\
\hline $\begin{array}{l}A(\text { all }) \\
(n=221) \\
100 \%\end{array}$ & $34.8 \%$ & $65.2 \%$ & $45.2 \%$ & $54.8 \%$ & $20.8 \%$ & $79.2 \%$ \\
\hline $\begin{array}{l}B(\text { claims }) \\
(n=161) \\
72.9 \% \text { of } A(\text { all })\end{array}$ & $42.2 \%$ & $57.8 \%$ & $52.2 \%$ & $47.8 \%$ & $24.8 \%$ & $75.2 \%$ \\
\hline $\begin{array}{l}C(\text { no claims }) \\
(n=60) \\
27.1 \% \text { of } A(\text { all })\end{array}$ & $15.0 \%$ & $85.0 \%$ & $26.7 \%$ & $73.3 \%$ & $15.0 \%$ & $85.0 \%$ \\
\hline
\end{tabular}

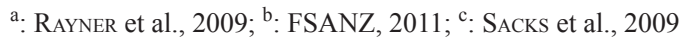

Table 3 presents the $2 \times 2$ tables obtained by comparing the nutrient/health label classification with the UK Ofcom model, FSANZ model and Traffic Light model classifications, respectively. The three tables reflect poor symmetry. McNemar's chi-square statistic is highly significant in all three cases, while its value is extremely high in the Traffic Light case. These results suggest that a certain product in the B (claims) group is more likely to be given the score "less healthy" with the Traffic Light model than with the UK Ofcom model and FSANZ model classifications. It should be noted that similar studies about nutritional quality of foods in the food supply were very recently also published for German (MAschкowski et al., 2014), New Zealand (Devi et al., 2014) and the UK market (KaUR et al., 2014).

Table 3. Number of items according to nutrition and health claims and according to "healthier" and "less healthy" status by the UK Ofcom model, FSANZ model, and Traffic Light model

\begin{tabular}{|c|c|c|c|c|c|c|c|}
\hline & \multicolumn{2}{|c|}{ UK Ofcom $^{\mathrm{a}}$} & \multicolumn{2}{|c|}{ FSANZ $^{b}$} & \multicolumn{2}{|c|}{ Traffic Light $^{\mathrm{c}}$} & \multirow[t]{2}{*}{ Total } \\
\hline & $\begin{array}{c}\text { HEALTHI- } \\
\text { ER } \\
\text { (<4 points })\end{array}$ & $\begin{array}{c}\text { LESS } \\
\text { HEALTHY } \\
\text { ( } \geq 4 \text { points })\end{array}$ & $\begin{array}{c}\text { HEALTHI- } \\
\text { ER } \\
(<4 \text { points })\end{array}$ & $\begin{array}{c}\text { LESS } \\
\text { HEALTHY } \\
\text { ( } \geq 4 \text { points) }\end{array}$ & $\begin{array}{c}\text { HEALTHI- } \\
\text { ER } \\
<7 \text { points }\end{array}$ & $\begin{array}{c}\text { LESS } \\
\text { HEALTHY } \\
\geq 7 \text { points }\end{array}$ & \\
\hline $\begin{array}{l}\text { Group B } \\
\text { (claims) }\end{array}$ & 68 & 93 & 84 & 77 & 37 & 124 & $161(72.9 \%)$ \\
\hline $\begin{array}{l}\text { Group C } \\
\text { (no claims) }\end{array}$ & 9 & 51 & 16 & 44 & 9 & 51 & $60(27.1 \%)$ \\
\hline $\begin{array}{l}\chi^{2} \text {-Statistics } \\
\text { P-value }\end{array}$ & \multicolumn{2}{|c|}{$\chi^{2}=14.28$} & \multicolumn{2}{|c|}{$\chi^{2}=11.50$} & \multicolumn{2}{|c|}{$\chi^{2}=97.71$} & \\
\hline
\end{tabular}

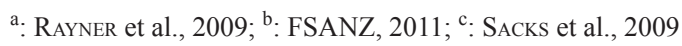

***: significant difference at $\mathrm{P}<0.001$ 


\section{Conclusions}

The use of nutrition and/or health claims on breakfast cereals is relatively poorly related to their nutrient profile as determined by the UK Ofcom, FSANZ or modified Traffic Light nutrient profile models. The share of specimens with claims $(72.9 \%)$ is far greater than the percentage of specimens considered as "healthier". For example, group A (all) contains $72.9 \%$ specimens with claims and only $34.8 \%$ (UK Ofcom model), $45.2 \%$ (FSANZ model), or $20.8 \%$ (Traffic Light model) of specimens scored "healthier" (details for other groups are given in Table 2). The difference is the most pronounced for the modified Traffic Light system, while the UK Ofcom and FSANZ systems come much closer to the use of claims. A certain product is most likely to pass as "healthier" if estimated by the FSANZ model and is most likely to be given the score of "less healthy" if treated by the modified Traffic Light model. The EU legislation on nutrient profiling is a constant concern, but it is a rather slow moving topic, at least since 2009. So is the use of nutrition, health, and related claims on the food labelling. The work is always behind the schedule, and the discrepancies described in this paper may well be one of the reasons.

Thanks are due to Murray Bales for providing assistance with the language.

\section{References}

Agresti, A. (1990): Categorical data analysis. Wiley, New York, 558 pages.

Azaïs-Braesco, V., Goffi, C. \& Labouze, E. (2006): Nutrient profiling: comparison and critical analysis of existing systems. Public Health Nutr., 9, 613-622.

CAPPuCCIO, F.P. \& Pravst, I. (2011): Health claims on foods: promoting healthy food choices or high salt intake? Br. J. Nutr., 106, 1770-1771.

Devi, A., Eyles, H., Rayner, M., Ni Mhurchu, C., Swinburn, B., Lonsdale-Cooperb, E. \& Vandevijverea, S. (2014). Nutritional quality, labelling and promotion of breakfast cereals on the New Zealand Market. Appetite, 81, 253-260.

EC (2006): Regulation No 1924/2006 of the European Parliament and of the Council of 20 December 2006 on nutrition and health claims made on foods. OJ L 404, 30.12.2006, 9-25.

EC (2011): Regulation No 1169/2011/EC of the European Parliament and of the Council of 25 October 2011 on the provision of food information to consumers. OJ L 304, 22.11.2011, 18-63.

EUFIC (2008): Characterizing the nutritional value of foods, using nutrient profiling. European Food Information Council, Brussels. Available at http://www.eufic.org/page/en/show/latest-science-news/fftid/Characterisingnutritional-value-foods-nutrient-profiling/ (accessed January, 2014).

FSA (2007): Front-of-pack Traffic light signpost labelling, Technical Guidance, Issue 2. Food Standard Agency, United Kingdom. Available at http://www.food.gov.uk/multimedia/pdfs/frontofpackguidance2.pdf (accessed February, 2014).

FSANZ (2011): Calculation method for determining foods eligible to make health claims: Nutrient profiling calculator. Food Standards Australia New Zealand, Canberra and Wellington. Available at http://www. foodstandards.gov.au/ srcfiles/method $\% 20$ to $\% 20$ determine $\% 20$ eligibility $\% 20$ final .pdf (accessed November, 2012).

Garsetti, M., De Vries, J., Smith, M., Amosse, A. \& Rolf-Pedersen, N. (2007): Nutrient profiling schemes: overview and comparative analysis. Eur. J. Nutr., 46, 15-28.

Kaur, A., Scarborough, P., Matthews, A., Payne, S., Mizdrak, A. \& Rayner, M. (2015) How many foods in the UK carry health and nutrition claims, and are they healthier than those that do not? Public Health Nutr. In Press (DOI:10.1017/S1368980015002104) 
Maschkowski, G., Hartmann, M. \& Hoffmann, J. (2014). Health-related on-pack communication and nutritional value of ready-to-eat breakfast cereals evaluated against five nutrient profiling schemes. BMC Publ. Health, 14, 1178 (DOI:10.1186/1471-2458-14-1178)

Pravst, I. (2012): Functional foods in Europe: a focus on health claims, scientific, health and social aspects of the food industry. -in: VALDEZ, B. (Ed.) Scientific, health and social aspects of the food industry. InTech, Rijeka, pp. 165-208.

Rayner, M., Scarborough, P. \& Lobstein, T. (2009): The UK Ofcom. Nutrient profiling model defining 'healthy' and 'unhealthy' foods and drinks for TV advertising to children. British Heart Foundation Health Promotion Research Group, Oxford. Available at http://www.dph.ox.ac.uk/bhfhprg/publicationsandreports/acadpublications/bhfhprgpublished/nutrientprofilemodel (accessed February, 2014).

R CoRe TeAm (2013): R: A language and environment for statistical computing. $\mathrm{R}$ Foundation for Statistical Computing, Vienna. Available at http://www.R-project.org/ (accessed February, 2014).

SACKs, G., RAYNER, M. \& SwinBURn, B. (2009): Impact of front-of-pack 'traffic-light' nutrition labelling on consumer food purchases in the UK. Health Promot. Int., 24, 344-352.

Sacks, G., Tikellis, K., Millar, L. \& Swinburn, B. (2011): Impact of 'traffic-light' nutrition information on online food purchases in Australia. Aust. NZ. J. Public Health, 35, 122-126.

Scarborough, P., Rayner, M. \& Stockley, L. (2007a): Developing nutrient profile models: a systematic approach. Public Health Nutr., 10, 330-336.

Scarborough, P., Boxer, A., Rayner, M. \& Stockley, L. (2007b): Testing nutrient profile models using data from a survey of nutrition professionals. Public Health Nutr., 10, 337-345.

Tetens, I., Oberdörfer, R., Madsen, C. \& De Vries, J. (2007): Nutritional characterisation of foods: Science-based approach to nutrient profiling. Eur. J. Nutr., 46, 4-14.

Trichterborn, J. \& Harzer, G. (2007): An industry perspective on nutrition profiling in the European environment of public health and nutrition. Nutr. Bull., 32, 295-302.

Verhagen, H. \& VAn Den Berg, H. (2008): A simple visual model to compare existing nutrient profiling schemes. Food Nutr. Res., 52. Available at http://10.3402/fnr.v52i0.1649.

WHO (2011): Nutrient profiling: Report of a WHO/IASO technical meeting, London, United Kingdom 4-6 October 2010. World Health Organization, London. Available at http://www.who.int/nutrition/topics/profiling/en/\# (accessed February, 2014). 